as a nanoscale reaction vessel in which to produce mineralized nanoparticles that have optical, catalytic or magnetic activity ${ }^{4}$, and packing nanoparticles into ordered assemblies leads to the emergence of collective behaviours that have found applications in opto-electronics, medicine and sensing ${ }^{5}$. Zhang and colleagues' findings might therefore provide a useful method for fine-tuning such collective phenomena by enabling controllable and reversible structural ordering in 3D nanoparticle arrays. Success will hinge on the identity and properties of the particles produced in the cavities of ferritin molecules, on the separation distances and ordering that the protein structure and crystal lattice impose on these nanoparticles, and on whether the kinetics of polymer expansion and contraction can be accelerated or otherwise precisely controlled.

Beyond ferritin, the use of other natural protein cages $^{4}$ - and, more excitingly, of synthetic protein cages designed from scratch ${ }^{6,7}$ - should provide the versatility needed to control nanoparticle separation distances and lattice systems. Furthermore, the development of creative polymer chemistry will aid efforts to modify the kinetics of expansion and contraction. -

François Baneyx is in the Department of Chemical Engineering, University of

Washington, Seattle, Washington 98195, USA. e-mail:baneyx@uw.edu

1. Zhang, L., Bailey, J. B., Subramanian, R. H. \& Tezcan, F. Nature 557, 86-91 (2018).

2. Lawson, D. M. et al. Nature 349, 541-544 (1991).

3. Roy, N., Bruchmann, B. \& Lehn, J.-M. Chem. Soc. Rev. 44, 3786-3807 (2015).

4. Rother, M., Nussbaumer, M. G., Renggli, K. \& Bruns, N. Chem. Soc. Rev. 45, 6213-6249 (2016).

5. Mann, S. Nature Mater. 8, 781-792 (2009)

6. Bale, J. B. et al. Science 353, 389-394 (2016).

7. Hsia, Y. et al. Nature 535, 136-139 (2016).

\title{
Molecular machines swap rings
}

A chemical system has been made in which two rings on an axle can switch places by allowing a smaller ring to slip through the cavity of a larger one. The advance opens up potential applications in molecular data storage.

\section{STEVE GOLDUP}

$\mathrm{M}$ any of the synthetic molecular machines ${ }^{1}$ that have been developed in the past 40 years are based on rotaxanes: molecules in which a ringshaped component encircles a linear axle that is terminated with large 'stoppers' to prevent the ring from slipping off. The threading of the axle through the ring limits the motion of the ring to shuttling back and forth along the axle. Such shuttling has been used in a range of molecular machines that includes switches ${ }^{2}$, ratchets ${ }^{3}$, pumps ${ }^{4}$ and smallmolecule synthesizers ${ }^{5}$. Rotaxanes in which more than one ring encircles the axle have also been made ${ }^{6}$, reminiscent of an abacus, but the rings have been unable to switch places. Writing in Nature Chemistry, Zhu et al. ${ }^{7}$ now report a system in which the rings can slip past one another, opening the way to new types of molecular machine.

To achieve a ring-through-ring shuttling motion, Zhu and colleagues assembled a rotaxane that contains two differently sized rings (Fig. 1). One has a circumference of 24 atoms, which is about as small as a ring can be in a rotaxane, whereas the other is almost twice as large at 42 atoms. Both rings form hydrogen bonds with nitrogen-hydrogen $(\mathrm{N}-\mathrm{H})$ units of the axle, and this enabled the authors to probe the rings' movement using nuclear magnetic resonance (NMR) spectroscopy.

At room temperature, the authors observed two distinct $\mathrm{N}-\mathrm{H}$ signals in the NMR spectrum of the rotaxane, because the signal for an $\mathrm{N}-\mathrm{H}$ unit that is bonded to the small ring appears at a different frequency from that of an $\mathrm{N}-\mathrm{H}$ unit bonded to the larger ring. This told Zhu and co-workers that the rings exchange places slowly at this temperature, or not at all. However, as the sample of rotaxane was heated, the signals began to broaden and then merged into a single peak. This finding confirmed that the rings change places quickly at elevated temperatures. The only way that this could have occurred is by the smaller ring passing through the larger one.

Zhu et al. determined that, at room temperature, the energy barrier that must be overcome for the rings to change places is about 52 kilojoules per mole of rotaxane, which corresponds to a shuttling rate of about 3,600 times per second. For comparison, in an analogous rotaxane that contains only the smaller ring, the ring hops between the $\mathrm{N}-\mathrm{H}$ groups approximately 80,000 times per second, or roughly 20 times faster. On the basis of this comparison, the authors estimate that the ring-throughring movement 'costs' about 12 kilojoules per

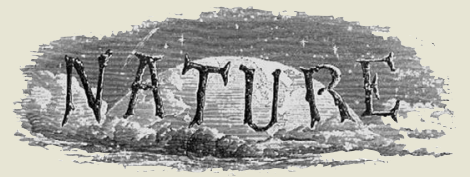

50 Years Ago

The British General Post Office is busy organizing a "telephone fortnight" in an attempt to silence the public criticism of its services. So far, the promotion has given everybody a chance to tell their favourite telephone stories, most of them unflattering to the GPO. The GPO's timing was inept; it is only two weeks since it announced increases in postal and telephone charges, and it might have been better to let the hubbub settle down before organizing the campaign ... In the next three years, the GPO is intending to spend $£ 1,100$ million on investment in telecommunications ... In the longer term, the GPO should be wondering how to increase the number of subscribers ... Britain still has very few telephones - 183 telephones per 1,000 of population. From Nature 4 May 1968

100 Years Ago

Students of animal behaviour will find some interesting facts on the "drumming" of the ruffed grouse ... in Forest and Stream for April, illustrated by a series of remarkable photographs, probably the first of the kind which have ever been taken. The author, Mr. F. K. Vreeland, had the good fortune to watch at close range one of these birds while "displaying", and he is convinced that the strange drumming sound then made is produced by the use of the wings alone. This may indeed be the case, but we suspect that later investigations will show that these sounds are at least partly vocal ... The author is apparently so much of an "outdoor naturalist" that he has never read any of the voluminous literature on this theme of courtship displays. But in some respects this adds rather than detracts from the value of his observations, since his records are made without bias.

From Nature 2 May 1918 